\title{
Risk indexes for studying interconnected earthing systems inside MV networks
}

\author{
A. Campoccia \& G. Zizzo \\ Department of Electrical, Electronic and Telecommunications \\ Engineering, University of Palermo, Italy
}

\begin{abstract}
The paper presents a risk-evaluation-based approach to the issue of interconnection between the earth electrodes of the MV/LV substations within MV networks. After a short introduction on the interconnection between earthing systems, the paper proposes four risk indexes defined starting from the safety requirements given by CENELEC HD $637 \mathrm{~S} 1$.

The indexes allow one to put in evidence, in a clear way, the benefits of the interconnection in terms of reduction of risk of critical electric shock for persons and of stress on the insulation of the LV devices in the presence of single line to earth faults and double earth faults inside MV/LV substations and single line to earth faults inside HV/MV stations. Moreover they can be used to identify in a simple way a Global Earthing System.
\end{abstract}

Keywords: risk indexes, electrical safety, global earthing systems.

\section{General problem}

Urban areas are characterized by earthing systems connected together so as to form a unique extended earthing system. An extended interconnection of earth electrodes can form a quasi-equipotential surface below the urban area, in which no dangerous voltages exist. In this case the interconnected earthing system can be defined "global earthing system" (GES in the following). The concept of GES was introduced for the first time in a normative document in 1999 [1] and, immediately it was clear its importance for electrical safety.

At a normative level, today, no universal criteria have been defined to identify a GES, but several distribution societies, private companies and research societies have given contributions to solve the problem [2-3]. All the methods 
proposed by the distribution societies base the identification of GES on earth impedance measurements or on geometrical criteria. However, while the first methods prove to be very expensive, the second do not take into account all the elements that contribute to the creation of a GES and are based on practical experiences on the specific MV networks belonging to the different distribution societies and not founded on universal parameters.

In recent years the authors have proposed analytical methods to identify GES based on the calculation of the earth potentials within substations areas during different fault conditions and on the check of the safety limits imposed by technical standards [4-7].

In this paper are proposed four risk indexes, which together with the abovementioned analytical methods can be used to recognize in an absolute way dangerous situations inside interconnected earthing systems and to eliminate their causes so as to improve safety and to obtain a GES.

\section{Methodology}

An earth fault within a MV or a HV network give rise to the following risks:

1. Electric shock risk for person due to high touch voltages (step voltages are generally less dangerous), defined by:

$$
R_{e s}=(1-S) \cdot K_{p}\left(t_{F}\right) \cdot \delta_{e s}\left(U_{T x}, t_{F}\right)
$$

2. Risk of excessive stress of the insulation of the LV equipments (only in TT-systems) due to high earth potential rises, defined by:

$$
R_{i s}=(1-S) \cdot K_{i}\left(t_{F}\right) \cdot \delta_{i s}\left(U_{E}, t_{F}\right)
$$

where:

- $\quad(1-S)$ is the frequency of occurrence of the earth fault;

- $\quad K_{p}$ is the probability of exposure of a person to a touch voltage during the fault;

- $K_{i}$ is the probability that the insulation of the electrical LV devices is exposed to the earth potential rise during the fault;

- $\delta_{e s}$ and $\delta_{i s}$ are, respectively, the damage for person, function of the maximum value of the touch voltage and of the fault duration $\left(U_{T x}, t_{F}\right)$ and the damage for the insulation of LV devices, function of the earth potential rise and of the fault duration $\left(U_{E}, t_{F}\right)$.

The permissible value of $R_{e s}$, indicated by $R_{e s A}$, is established on the basis of the typical values of $(1-S)$ and $K_{p}$ for MV and HV single line to earth fault, imposing a permissible damage $\delta_{\text {esA }}$ starting from the curves giving the danger of the current through human body as function of the fault duration [8]. Passing from the curve of the hazardousness of the body current, through the resistance of the human body, to the curve of hazardousness of the touch voltage as function of the fault duration, it's possible to express $R_{e s A}$ in the following way: 


$$
R_{e s A}=(1-S) \cdot K_{p}\left(t_{F}\right) \cdot \delta_{e s A}\left(U_{T p}, t_{F}\right)
$$

In fig. 1 the damage $\delta_{e s}$ is represented as a function of $U_{T}$ for different values of the fault duration. According to CENELEC HD 637-S1 the admissible damage has been calculated assuming a probability of ventricular fibrillation equal to $50 \%$ : (in terms of damage it may corresponds to $\delta_{e s A}=0.5: 50 \%$ of people can die as a consequence of the fault).

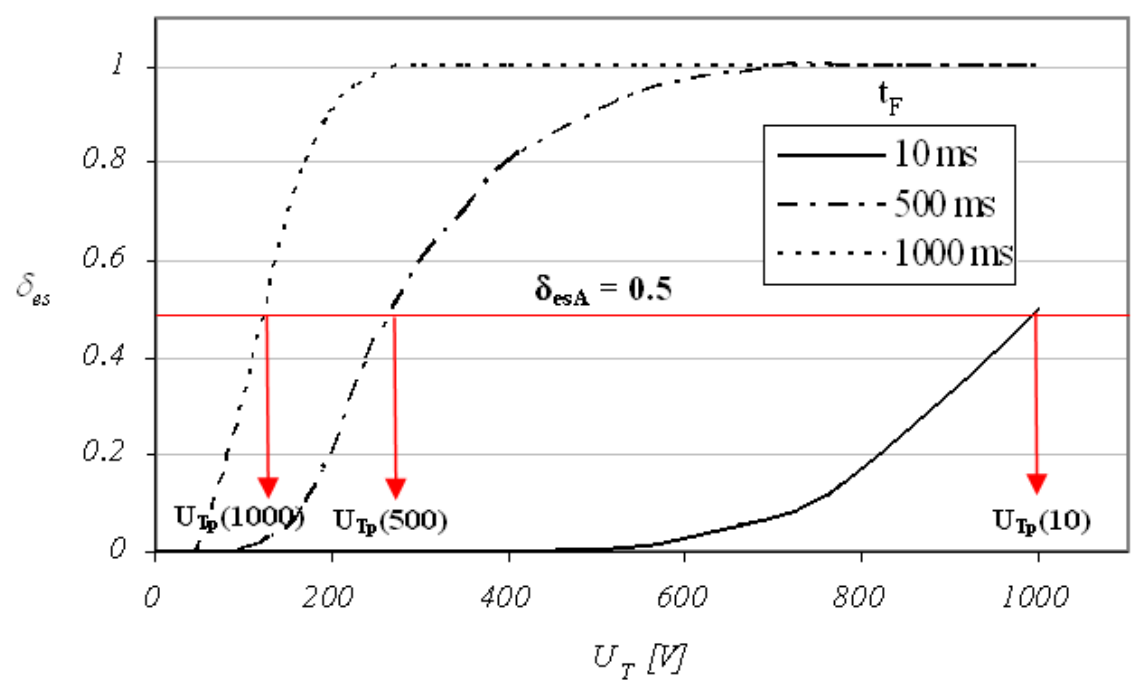

Figure 1: Damage $\delta_{e s}$ as function of $U_{T}$.

Close to the admissible damage and for typical values of $t_{F}$ (no lower than $100 \mathrm{~ms}$ ), the curves represented in fig. 1 can be approximated by straight lines and so it can be written:

$$
\frac{R_{e s}}{R_{e s A}}=\frac{\delta_{e s}\left(U_{T x}, t_{F}\right)}{\delta_{e s A}\left(U_{T p}, t_{F}\right)}=\frac{U_{T x}}{U_{T p}}
$$

From (4) it derives:

$$
R_{e s}=\frac{U_{T x}}{U_{T p}} \cdot R_{e s A}
$$

The permissible value of the risk for insulation, instead, is established on the basis of the maximum value of the earth voltage which the LV equipments insulation can stand and is given by:

$$
R_{i s A}=(1-S) \cdot K_{i}\left(t_{F}\right) \cdot \delta_{i s A}\left(U_{O}, t_{F}\right)
$$


In fig. 2 is represented the damage $\delta_{i s}$ as function of $U_{E}$. The two curves graphically represent the two situations expected from CLC HD 637 S1 and IEC 61936-1 CDV.

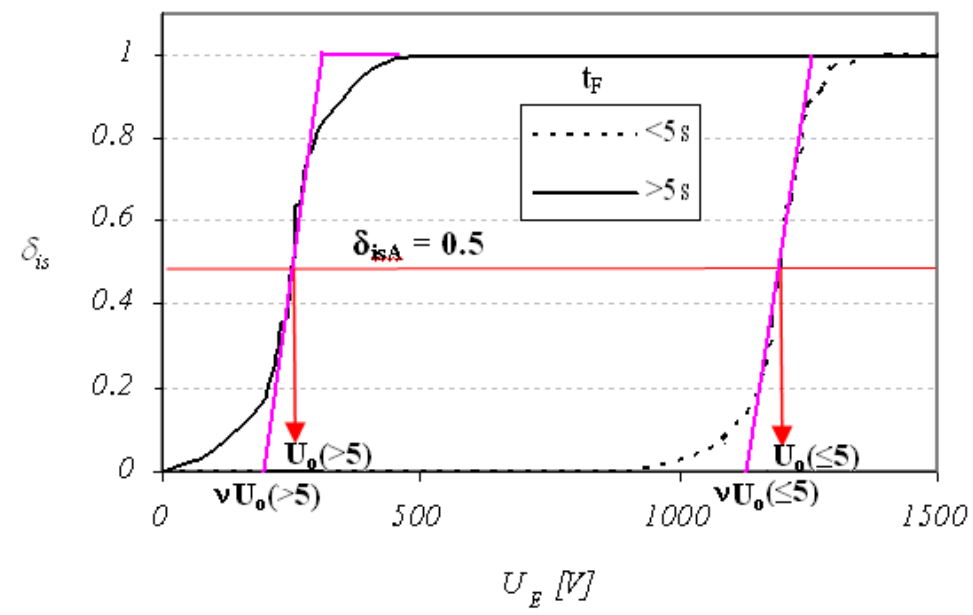

Figure 2: $\quad$ Damage $\delta_{i s}$ as function of $U_{E}$.

Close to the admissible damage, the curves represented in fig. 2 can be approximated by polylines (purple curves) and so it can be written:

$$
\frac{R_{i s}}{R_{i s A}}=\frac{\delta_{i s}\left(U_{E}, t_{F}\right)}{\delta_{i s A}\left(U_{O}, t_{F}\right)}=\frac{U_{E}-v \cdot U_{O}}{(1-v) \cdot U_{O}}
$$

where $v$ is about 0.75 .

From (7) it derives:

$$
R_{i s}=\frac{U_{E} / U_{O}-v}{1-v} \cdot R_{i s A}
$$

Equations (5) and (8) suggest that the evaluation of $R_{e s}$ and $R_{i s}$ can be done in a simply way by calculating the rates $U_{T x} / U_{T p}$ and $U_{E} / U_{O}$.

If $U_{T X} / U_{T p} \leq 1$ for all the possible fault conditions, the system is safe $\left(R_{e s} \leq R_{e s A}\right)$ for person, if $U_{O} / U_{E} \leq 1$ for all the possible fault conditions, there are no dangers for the insulation of the LV devices $\left(R_{i s} \leq R_{i s A}\right)$.

On the basis of this consideration it's possible to define four risk indicators to evaluate the safety conditions of a given earthing system with reference to the following fault conditions:

- $\quad$ single-line-to-earth fault inside a MV/LV substation (event $E_{l}$ )

- $\quad$ single-line-to-earth fault inside a HV/MV station supplying a MV network (event $E_{2}$ ); 
- $\quad$ double-line-to-earth faults involving two MV/LV substations (event $E_{3}$ ).

These indicators, named relative risk index, are based on the assumption that as higher is the difference between the normative limit and the dangerous voltage due to a given event $E_{i}$ (with $\mathrm{i}=1,2, \ldots$ ), as lower is the risk related to that event. The first three indicators are related with danger of electric shock for person and can be defined in the following way:

$$
S=\frac{U_{T x, E 1}}{U_{T p, E 1}} ; \quad H=\frac{U_{T x, E 2}}{U_{T p, E 2}} ; \quad D=w_{D} \cdot \frac{U_{T x, E 3}}{U_{T p, E 3}}
$$

where $U_{T x, E i}$ is the highest value of the touch voltage within a substation area due to the event $E_{i}$ and $U_{T p, E i}$ is the permissible touch voltage related to event $E_{i}$ duration. Since $R_{e s A}$ and $\mathrm{R}_{i s A}$ have been defined with reference to the frequency of occurrence of a single line to earth fault, $w_{D}$ is a coefficient whose value is lower than 1, introduced to take into account the lower value of the frequency of occurrence (about 35\%) of the double earth fault with respect to a single line to earth fault.

The fourth index is related to the insulation stress and, according to (8), is defined in the following way:

$$
I S=\frac{1}{1-v} \cdot\left(\max \left\{\frac{U_{E, E 1}}{U_{O, E 1}} ; \frac{U_{E, E 2}}{U_{O, E 2}} ; w_{D} \cdot \frac{U_{E, E 3}}{U_{O, E 3}}\right\}-v\right)
$$

where $U_{E, E i}$ indicates the earth potential rise within a substation area due to event $E_{i}$ and $U_{O, E i}$, is the permissible voltages for insulation of the $\mathrm{LV}$ equipment calculated as function of the durations of the event $E_{i}$.

In table 1 are quoted the risk indexes that must be considered, for each substation, dependently from the state of the neutral point of the MV network (isolated neutral or resonant earthed neutral) and from the type of LV system earthing (TT or TN).

\begin{tabular}{|c|c|c|c|c|}
\hline & \multicolumn{2}{|c|}{ Isolated Neutral } & \multicolumn{2}{|c|}{ Resonant earthed neutral } \\
\hline LV system & TT & TN & TT & $\mathbf{T N}$ \\
\hline $\mathbf{S}$ & $\checkmark$ & $\checkmark$ & $\sqrt{ }$ & $\checkmark$ \\
\hline D* & $\checkmark$ & $\checkmark$ & & \\
\hline $\mathbf{H * *}$ & $\checkmark$ & $\checkmark$ & $\checkmark$ & $\checkmark$ \\
\hline IS*** & $\checkmark$ & & $\checkmark$ & \\
\hline \multicolumn{5}{|c|}{$\begin{array}{l}\text { * D must not be considered for resonant earthed neutral networks because the double } \\
\text { earth fault in these networks is highly improbable }\left(1-S_{3}\right) \approx 0 \text {. } \\
* * \mathrm{H} \text { must be considered only in presence of interconnected earthing systems and if the } \\
\text { earth electrode of a HV/MV station is included in the interconnected earthing system. } \\
* * * \text { IS must be considered only if the neutral of the LV systems is connected to the } \\
\text { earthing system of the substation. }\end{array}$} \\
\hline
\end{tabular}

Table 1: $\quad$ Table of the risk indexes.

Using the four indexes it is possible to write (5) and (8) as follows: 
72 Risk Analysis V: Simulation and Hazard Mitigation

$$
\begin{gathered}
R_{e s}=\max \{S ; D ; H\} \cdot R_{e s A} \\
R_{i s}=I S \cdot R_{i s A}
\end{gathered}
$$

The diagram in fig. 1 represents the procedure to evaluate the safety level of an interconnected earthing system in a MV network using the four indexes defined.

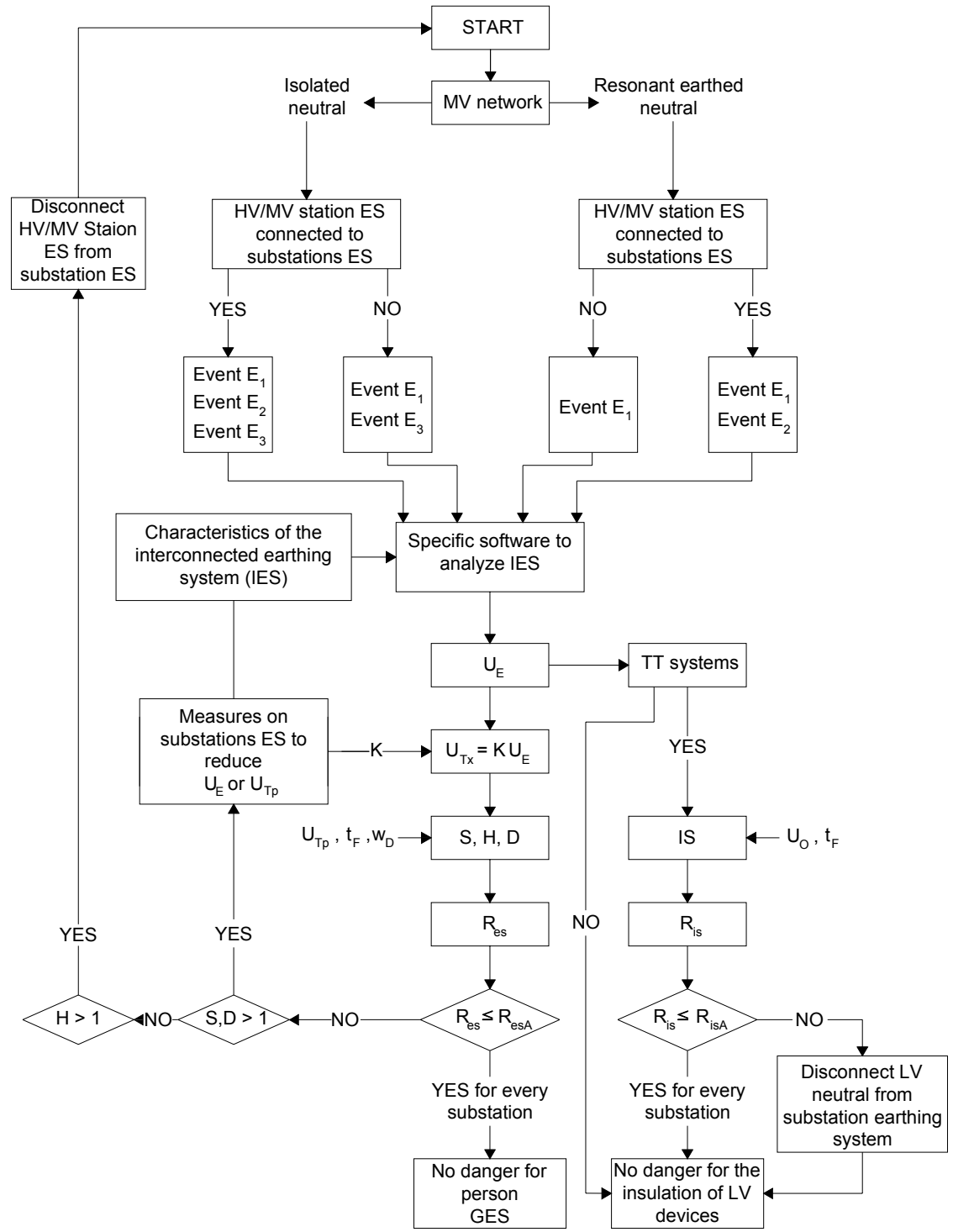

Figure 3: $\quad$ Evaluation of $R_{e s}$ and $R_{i s}$. 


\section{Application example}

The approach based on the calculation of the defined risk index has been applied to the network shown in figure 4 . The network is made by $10 \mathrm{MV}$ lines and $200 \mathrm{MV} / \mathrm{LV}$ substations (20 per line). The distance between the substations is equal to $300 \mathrm{~m}$.

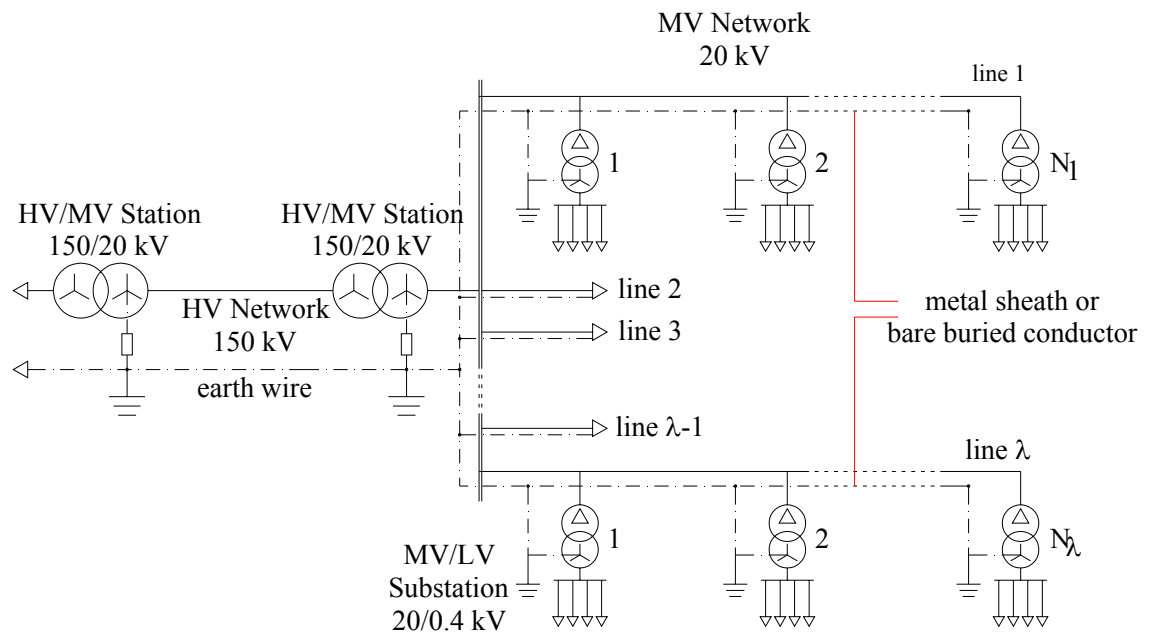

Figure 4: Schematic representation of the network.

In the calculation three situations have been considered: earth electrodes of the substations isolated, connected through the metal sheaths of three-core MV cables or connected through bare buried conductors (cross-section $35 \mathrm{~mm}^{2}$ ).

For the considered network the single line to earth fault current in the MV network is equal to $185 \mathrm{~A}$ while the single line to earth fault current within the $\mathrm{HV} / \mathrm{MV}$ station is equal to $10.5 \mathrm{kA}$. Depending on the events durations, the permissible touch voltages are $U_{T p, E I}=133 \mathrm{~V}\left(t_{F, E I}=690 \mathrm{~ms}\right)$ for isolated earthed neutral network, $U_{T p, E I}=75 \mathrm{~V}\left(t_{F, E I}>>10 \mathrm{~s}\right)$ for resonant earthed neutral network, $U_{T p, E 2}=U_{T p, E 3}=750 \mathrm{~V}\left(t_{F, E 2}=t_{F, E 3}=100 \mathrm{~ms}\right)$.

Specific coefficients, defined in [10], can be used for the calculation of touch and step voltages within substations areas starting from the earth potential rise $\mathrm{U}_{\mathrm{E}}$.

Assuming that all the earth electrodes of the MV/LV substations have the same shape and dimensions (figure 5) and that the earth bulk resistivity is equal to $100 \Omega \mathrm{m}$, the highest value of the touch voltage can be calculated as follow:

$$
U_{T x}=K \cdot U_{E}=0.3 \cdot U_{E}
$$




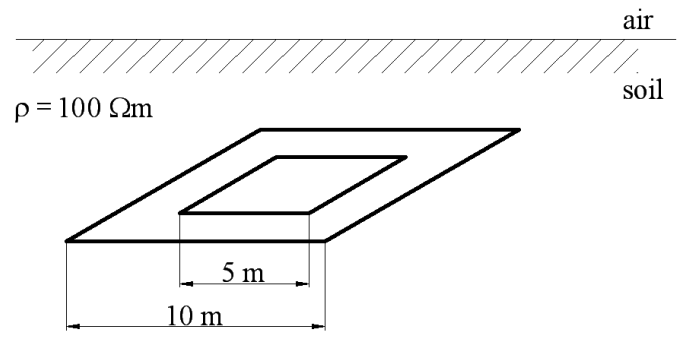

Figure 5: Shape of the earthing system of a substation.

In the following, the four risk indexes have been calculated for the $10^{\text {th }}$ substation of a MV line in the case of:

- $\quad$ single line to earth fault inside the substation;

- $\quad$ double earth fault at substations 10 and 11 (worst situation for substation 10 with reference to the double earth fault);

- $\quad$ single line to earth fault inside the HV/MV station.

Table 2: $\quad$ Results of the simulations.

\begin{tabular}{|c|c|c|c|c|c|c|c|c|}
\hline & \multicolumn{4}{|c|}{ Isolated Neutral } & \multicolumn{4}{|c|}{ Resonant Earthed Neutral } \\
\hline & $\mathbf{S}$ & $\mathbf{D}$ & $\mathbf{H}$ & IS & $\mathbf{S}$ & D & H & IS \\
\hline $\begin{array}{l}\text { Isolated earthing } \\
\text { systems }\end{array}$ & 2.09 & 1.21 & -- & 11.20 & 1.00 & -- & -- & 1.00 \\
\hline $\begin{array}{l}\text { Interconnection } \\
\text { by metal sheaths }\end{array}$ & 0.15 & 0.20 & 0.047 & 0.65 & 0.061 & -- & 0.047 & 0.10 \\
\hline \multirow{2}{*}{$\begin{array}{l}\text { Interconnection } \\
\text { by bare buried } \\
\text { conductors }\end{array}$} & 0.025 & 0.17 & 0.0023 & 0.39 & 0.033 & -- & 0.0023 & 0.022 \\
\hline & \multicolumn{2}{|c|}{$\mathbf{R}_{\mathrm{es}}$} & \multicolumn{2}{|c|}{$\mathbf{R}_{\text {is }}$} & \multicolumn{2}{|c|}{$\mathbf{R}_{\mathrm{es}}$} & \multicolumn{2}{|c|}{$\mathbf{R}_{\text {is }}$} \\
\hline $\begin{array}{l}\text { Isolated earthing } \\
\text { systems }\end{array}$ & \multicolumn{2}{|c|}{$2.09 R_{e s A}$} & \multicolumn{2}{|c|}{$11.20 R_{i s A}$} & \multicolumn{2}{|c|}{$R_{e s A}$} & \multicolumn{2}{|c|}{$R_{i s A}$} \\
\hline $\begin{array}{l}\text { Interconnection } \\
\text { by metal sheaths }\end{array}$ & \multicolumn{2}{|c|}{$0.20 R_{e s A}$} & \multicolumn{2}{|c|}{$0.65 R_{i s A}$} & \multicolumn{2}{|c|}{$0.061 R_{e s A}$} & \multicolumn{2}{|c|}{$0.10 R_{i s A}$} \\
\hline $\begin{array}{l}\text { Interconnection } \\
\text { by bare buried } \\
\text { conductors }\end{array}$ & \multicolumn{2}{|c|}{$0.17 R_{e s A}$} & \multicolumn{2}{|c|}{$0.39 R_{i s A}$} & \multicolumn{2}{|c|}{$0.033 R_{e s A}$} & \multicolumn{2}{|c|}{$0.022 R_{i s A}$} \\
\hline
\end{tabular}

Table 2 shows a typical example of what happens within an interconnection of earthing systems of substations during an earth fault. For all the situations the interconnection allows to obtain great advantages in terms of reduction of the risk indexes $S, D$ and $I S$. In absence of interconnection the only way to make safe the earth electrode of the $10^{\text {th }}$ substation is to reduce $U_{E}$ or $U_{T}$, and both the solutions need an intervention on the structure of the earth electrode.

The use of bare buried conductors appears to be the must advantageous way to reduce all the risks due to the faults in the MV and HV networks. 


\section{Conclusion}

The construction of risk matrices whose elements are the relative risk indexes $S$, $D, H$ and $I S$ calculated for every MV/LV substation and for every fault situation in a given MV network, allows to evaluate the effectiveness of the interconnection between substations earthing systems. The risk matrices of a MV network are real risk maps for that network and can be used to have a clear vision of which substations are safer and which are, on the contrary, more easily influenced by the possible changes of the MV network. If all the elements of the matrices have values not over 1, the network is safe both for person and for the insulation of the LV devices. In particular, if all the elements of the risk matrices related to the indexes $S, D$ and $H$ are not over 1 the extended earthing system is a GES.

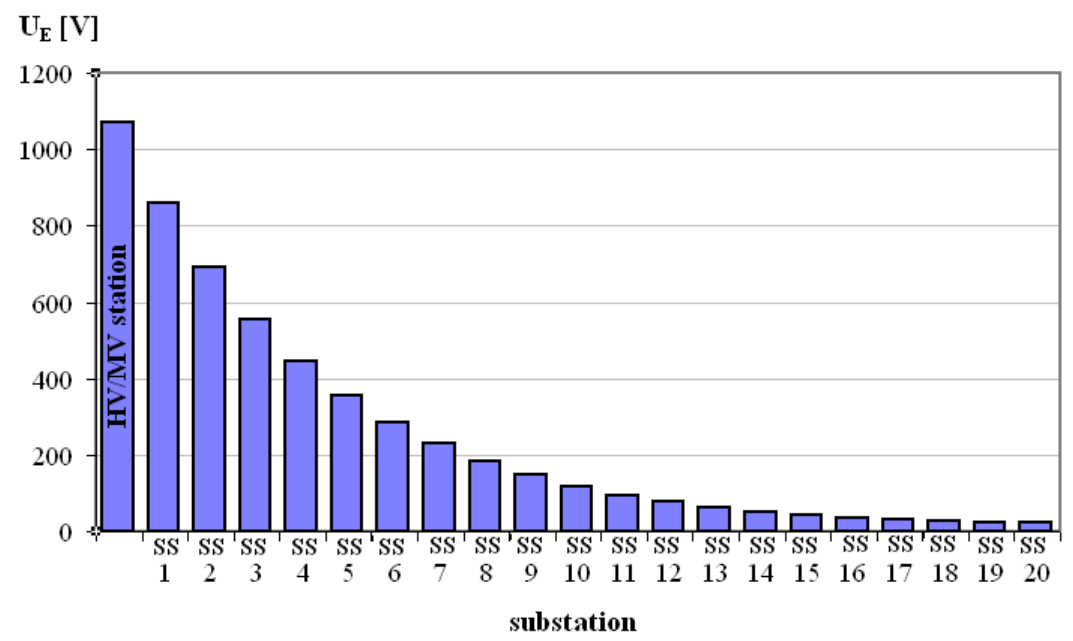

Figure 6: $\quad$ Earth potential rise at the substations (SS) due to an Event $E_{2}$.

Table 3: $\quad$ Example of an S-risk matrix.

\begin{tabular}{|c|c|c|c|c|c|}
\hline \multirow{2}{*}{\multicolumn{2}{|c|}{}} & \multicolumn{4}{|c|}{ Substation number } \\
\cline { 3 - 6 } & $\mathbf{1}$ & $\mathbf{2}$ & $\ldots$ & $\mathbf{N}$ \\
\hline & $\mathbf{1}$ & 0.10 & 0.12 & $\ldots$ & 0.17 \\
\hline & $\mathbf{2}$ & 0.17 & 0.21 & $\ldots$ & 0.25 \\
\hline & $\ldots$ & $\ldots$ & $\ldots$ & $\ldots$ & $\ldots$ \\
\hline & $\lambda$ & 0.19 & 0.19 & $\ldots$ & 0.22 \\
\hline & & & & & \\
\hline
\end{tabular}

In a preliminary phase, using the new risk matrices deriving from a transformation of the MV network (expansion, reconfiguration, transformation 
from aerial to cable line or vice versa), it's possible to define if the transformation that is to be done can increase the risks for the network.

Moreover, the H-risk matrix can be used to establish if it's possible to connect the earth electrode of the HV/MV station to the earth electrodes of the MV/LV substations. Indeed, such a connection is possible only if $H$ is not higher than 1 for all the substations belonging to the interconnected earthing system.

If all the substations earth electrodes are identical, the highest value of $H$ can be calculated considering the first substation of every MV line outgoing the $\mathrm{HV} / \mathrm{MV}$ station. Indeed, as figure 6 shows, the potentials transferred to the earth electrodes of the substations during an earth fault inside the station decrease as distance from the fault location.

\section{References}

[1] CENELEC HD 637 S1-1999E, Power installations exceeding $1 \mathrm{kV}$ a.c. 1999.

[2] Desmedt, M., Hoeffelman, J., Halkin, D., Use of a global earthing system to implement the safety requirements for protecting against indirect contacts in HV systems. Proc. of CIRED 2001, Conference Publication n482, 2001.

[3] Mosciatti, M., L'impianto di terra globale: sicurezza nuova per gli impianti elettrici. La soluzione Enel per la città di Pesaro. AEI Seminar, 8 febbraio 2000, Ancona, Italy.

[4] Campoccia, A., Mineo, L., Un modello per lo studio di sistemi di impianti di terra interconnessi in una rete in MT a neutro isolato. L'Energia elettrica, 75(6), pp. $357-368,1998$.

[5] Campoccia, A., Di Silvestre, M.L., Mineo, L., Una metodologia di analisi di impianti di terra interconnessi tramite i rivestimenti metallici dei cavi MT in reti a neutro isolato. L'Energia elettrica, 76(4), pp. 425 - 434, 1999.

[6] Campoccia, A., Zizzo, G., A study of the behaviour of earth electrodes connected together in resonant earthed neutral network. Safe and Security Engineering - WIT Transaction on the Built Environment Vol. 82, pp. 93 102, 2005.

[7] Campoccia, A., Mineo, L., Zizzo, G., A method to evaluate voltages to earth during an earth fault on a HV network in a system of interconnected earth electrodes of MV/lv substations. Proc. of OPTIM 2004, Conference Publication A-20, 2004.

[8] IEC Tech. Rep. 1200-413 Ed. I, Measures against indirect contact by automatic disconnection of supply, 1996.

[9] Cataliotti, V., Campoccia, A., Dispersori di piccole dimensioni (Chapter 3). Impianti di terra, eds. TNE: Italy, pp. 75-114, 2003. 